\title{
Role of Cardiac Troponin I level in predicting in-hospital outcomes in patients with ST-segment elevation myocardial infarction in Erbil-Iraq
}

Salam Naser Zangana * Abdulkareem A.AL-Othman ** Namir G.AL-Tawil ${ }^{* \star *}$

\begin{abstract}
Background and objectives: The correlation of cardiac troponin I with early in-hospital outcomes in acute myocardial infarction is not well established.
\end{abstract}

This study aims to assess the role of troponin I in predicting in-hospital outcomes and early left ventricular systolic dysfunction in patients with ST-segment elevation myocardial infarction (STEMI).

Patients and methods: In a prospective study, 116 patients (74males and 42 females), with STEMI who had been admitted to the Coronary CareUnit from March 2015 to September 2015 were enrolled. Patients were divided according to the level of troponin I on admission into 3 groups (low, medium and high elevation).

Results: The mean age ( \pm SD) of the patients was $60 \pm 11.4$ years. The troponin level of $66.2 \%$ of males was high compared with $52.4 \%$ of females $(p=0.002)$. The incidence of acute pulmonary edema $(21.1 \%)$, cardiogenic shock (7\%) and early left ventricular systolic dysfunction (49.3\%) was significantly higher among patients with high troponin level compared with $(0 \%, 0 \%$ and $16 \%$, respectively) among patients with low troponin level. All deaths and cardiac arrest were of high troponin level.

Conclusions: High admission troponin I in STEMI permits early identification of patients at increased risk of major cardiac complications and death.

Keywords: Cardiac troponin I, Ischemic heart disease

*(Corresponding author) M.B.Ch.B, DM, CABMS, FICMS. Senior Lecturer, Department of Medicine, College of Medicine, Hawler Medical University, Erbil-Iraq. E-mail: dr_salam2003@yahoo.com.

${ }^{* *}$ M.B.Ch.B, F.I.C.M.S. Professor of Medicine, Department of Medicine, College of Medicine. 
Hawler Medical University, Erbil-Iraq

${ }^{* * *}$ M.B.Ch.B, F.I.C.M.S/CM, FFPH.Professor of Community Medicine, Department of Community Medicine, College of Medicine.

\section{Introduction:}

According to the world health rankings, data source published by World Health organization (WHO) 2014,the age-adjusted death rate of coronary heart disease in Iraq was 187.65 per 100,000 populations. Iraq's rank was 22 worldwide and the second in Arab countries for the death due to CHD [1].

The Cardiac specific Troponin I (cTn-I) is expressed only in cardiac muscle, which allows this biomarker to be highly specific for myocardial damage [2]. In STEMI, the prognostic properties of cardiac troponins are influenced by the sampling time-point. A positive cardiac troponin on admission is probably reflective of longer ischemic time and more extensive myocardial necrosis, and consequently predictive of clinical outcomes [3]. There are some data suggesting that a negative troponin result reflects a good prognosis due to low incidence of cardiac death or non-fatal Ml at 30 days [4].

As a marker of infarct size, cTnl is related to the extent of left ventricular remodeling and risk for development of chronic left ventricular dysfunction; and it improves prediction of these end points when added to the conventional risk stratification approach by assessment of left ventricular ejection fraction (LVEF) and volumes before discharge [5].

The correlation between admission cTnl level and the development of early left ventricular systolic dysfunction was not well defined.Up to our knowledge, there was no previous study done in Iraq. 
The aim of the present study is to evaluate the role of admission cardiac troponin I level in predicting inhospital outcome and early left ventricular systolic dysfunction (LVSD) in patients presenting with ST-segment elevation myocardial infarction.

\section{Patients and Methods}

This prospective study (case series) was conducted in the Coronary Care Unit (CCU) of Rizgary and Erbil teaching hospital between March 2015 and September 2015. A total of 116 consecutive patients presenting with chest painof 12 hours duration or less, were enrolled in the study.

The inclusion criteria were acute myocardial infarction for the $1^{\text {st }}$ time, in patients with chest pain of 12 hours duration or less, and there was no chance to do early coronary angiography, percutaneous coronary intervention $(\mathrm{PCl})$ or coronary artery bypass grafting $(\mathrm{CABG})$. The patients presented within 12 hours were given thrombolytic therapy unless there was an obvious contraindication, and after that they were treated according to the management of the physician.

The patients who presented with the following were excluded from the study: a-Previous history of myocardial infarction, $\mathrm{PCl}$ or CABG. b-Previous history of heart failure proved clinically or by echocardiography cCongenital or valvular heart diseases $d$-Left bundle branch block (LBBB).

The diagnosis of acute STEMI was based on the following criteria: Typical rise and/or fall of troponin with at least one of the following: a- Ischemic symptoms b-Electrocardiographic changes indicative of ischemia (STsegment elevation ) [6].

In this study,demographic variables, cardiovascular risk factors and physical examination for the Killip-Kimball classification(Killip class) [7],were obtained. All patients were studied prospectively without knowledge of the admission Troponin I levels for early in-hospital outcomes including cardiac standstill, arrhythmias and mortality. Resting Electrocardiography (ECG) and transthoracic Echocardiography was done to all patients to assess the left ventricular systolic dysfunction (which was defined as ejection fraction ejection fraction $<50 \%$ in the absence of significant ischemic mitral regurgitation, or ejection fraction $<55 \%$ in the presence of ischemic mitral regurgitation) [8]. 
Venous blood was withdrawn from patients at the time of admission. The blood sample was separated for a lot of laboratory markers including Troponin I,the normal value was $0.0-0.4 \mathrm{ng} / \mathrm{ml}(>0.4 \mathrm{ng} / \mathrm{ml}$ is abnormal) according to kit reference value, assessed by Biomerieux kit with enzyme-linked fluorescent assay (ELFA).

Patients were categorized into 3 groups according to the level of Troponin I at admission. Group-I patients with mildly elevated level (one fold elevation), Group-II patients with moderately elevated level (2-3 fold elevation), and Group-III patients with highly elevated level (> 3 fold elevation) [9]. All groups were evaluated and compared according to the baseline characteristics of the study population (demographics and risk factors), Global Registry of Acute Coronary Events (GRACE) risk score, in-hospital outcomes or complications and echocardiographic findings. GRACE risk score was also categorized into 3 groups, group A (low risk <126), group B (intermediate risk 126-154), and group C (high risk >154) [10].

Verbal informed consent was obtained from all patients, and the protocol was approved by theEthics Committee of the College of Medicine of Hawler Medical University.

\section{Statistical analysis}

The statistical package for social sciences (SPSS, version 19) was used for data analysis. Chi square test of association was used to compare proportions. Fisher's exact test was used when the expected count of more than $20 \%$ of the cells of the table was less than 5 . P-value of $\leq 0.05$ was considered as statistically significant.

\section{Results:}

A total of 116 patients with first time acute ST-segment elevation myocardial infarction were included in the present study. The mean age $( \pm S D)$ was $60 \pm 11.4$ years ranging from 33-99 years. Most patients were males $(63.7 \%)$. The troponin level of $66.2 \%$ of males was high compared with $52.4 \%$ of females $(P=0.002)$. Family history of IHD shows statistically significant association with high troponin level $(P=0.049)$. Although other socio-demographic and clinical variables did not show any statistically significant association with troponin level, it is worth to mention that a relatively high proportion of diabetics, hyperlipidemics, and smokers had high troponin levels $(p>0.05)$.as shown in Table 1.

There was a statistically significant association between troponin levels and risk according to GRACE score. Patients with high troponin levels had high risk GRACE score $(P=0.026)$, as shown in Table 2. 
Table 3 shows no significant association between in- hospital death and cardiac arrest at admission with troponin level. It is worth to mention that all deaths (four cases), serious arrhythmias(4 cases) were of high troponin level. The same table shows that $7 \%$ of those with high troponin level developed cardiogenic shock (KILLIP class IV) compared with $0 \%$ among those with low and medium troponin level. In addition to that, $21.1 \%$ of those with high troponin developed acute pulmonary oedema(KILLIP class III) heart failure compared with $11.1 \%$ among those with medium troponin and $0 \%$ among those with low troponin, while the majority of those with low troponin level developed KILLIP class 1 and II $(p=0.011)$.

The incidence of early LVSD (49.3\%) was significantly higher among patients with high troponin levels $(P=0.001)$. It is worth to mention that 3 of 4 patients with severe IMR had high troponin levels compared to $(0)$ patient with low troponin level as shown in Table 4.

Table 1.Troponin-I levels by socio-demographic and clinical variables.

\begin{tabular}{|c|c|c|c|c|c|c|c|c|}
\hline & \multirow[t]{3}{*}{$\mathbf{N}$} & \multicolumn{6}{|c|}{ Troponin-I } & \multirow[t]{3}{*}{$\mathbf{p}$} \\
\hline & & \multicolumn{2}{|c|}{ Low } & \multicolumn{2}{|c|}{ Medium } & \multicolumn{2}{|c|}{ High } & \\
\hline & & No. & $\%$ & No. & $\%$ & No. & $\%$ & \\
\hline \multicolumn{9}{|c|}{ Age (years) } \\
\hline$<50$ & 16 & 4 & 25 & 1 & 6.3 & 11 & 68.8 & $0.102^{*}$ \\
\hline $50-59$ & 42 & 14 & 33.3 & 9 & 21.4 & 19 & 45.2 & \\
\hline $60-69$ & 31 & 3 & 9.7 & 6 & 19.4 & 22 & 71 & \\
\hline$\geq 70$ & 27 & 6 & 22.2 & 2 & 7.4 & 19 & 70.4 & \\
\hline \multicolumn{9}{|l|}{ Gender } \\
\hline Male & 74 & 10 & 13.5 & 15 & 20.3 & 49 & 66.2 & 0.002 \\
\hline Female & 42 & 17 & 40.5 & 3 & 7.1 & 22 & 52.4 & \\
\hline \multicolumn{9}{|c|}{ BMI categories } \\
\hline$<25$ & 63 & 20 & 31.7 & 11 & 17.5 & 32 & 50.8 & $0.277^{*}$ \\
\hline $25-29$ & 33 & 4 & 12.1 & 5 & 15.2 & 24 & 72.7 & \\
\hline $30-34$ & 17 & 3 & 17.6 & 2 & 11.8 & 12 & 70.6 & \\
\hline
\end{tabular}




\begin{tabular}{lcccccccc}
\hline$\geq 35$ & 3 & 0 & 011 & 0 & 0 & 3 & 100 & \\
Diabetes & & & & & & & & \\
No & 84 & 21 & 25 & 15 & 17.9 & 48 & 57.1 & 0.319 \\
Yes & 32 & 6 & 18.8 & 3 & 9.4 & 23 & 71.9 &
\end{tabular}

Hypertension

$\begin{array}{lcccccccc}\text { No } & 53 & 9 & 17 & 11 & 20.8 & 33 & 62.3 & 0.182 \\ \text { Yes } & 63 & 18 & 28.6 & 7 & 11.1 & 38 & 60.3 & \end{array}$

Hyperlipidemia

$\begin{array}{lcccccccc}\text { No } & 35 & 9 & 25.7 & 7 & 20 & 19 & 54.3 & 0.557 \\ \text { Yes } & 81 & 18 & 22.2 & 11 & 13.6 & 52 & 64.2 & \end{array}$

Smoking

$\begin{array}{lllllllll}\text { No } & 64 & 19 & 29.7 & 8 & 12.5 & 37 & 57.8 & 0.163 \\ \text { Yes } & 52 & 8 & 15.4 & 10 & 19.2 & 34 & 65.4 & \end{array}$

Alcohol drinking

$\begin{array}{lcccccccc}\text { No } & 111 & 26 & 23.4 & 16 & 14.4 & 69 & 62.2 & 0.250^{*} \\ \text { Yes } & 5 & 1 & 20 & 2 & 40 & 2 & 40 & \end{array}$

Family history of IHD**

$\begin{array}{lllllllll}\text { No } & 87 & 23 & 26.4 & 16 & 18.4 & 48 & 55.2 & 0.049 \\ \text { Yes } & 27 & 3 & 11.1 & 2 & 7.4 & 22 & 81.5 & \end{array}$

Thrombolytic

therapy

\begin{tabular}{lllllllll} 
No & 63 & 20 & 31.7 & 12 & 19 & 31 & 49.2 & 0.014 \\
Yes & 53 & 7 & 13.2 & 6 & 11.3 & 40 & 75.5 & \\
\hline
\end{tabular}

*By Fisher's exact test. ${ }^{* *}$ There is missing data

Table 2. Association between troponin levels and GRACE ${ }^{+}$score.

\begin{tabular}{llll}
\hline Troponin-l & $\mathbf{N}$ & Risk according to GRACE $^{+}$score & $\mathbf{p}$ \\
\hline
\end{tabular}




\begin{tabular}{|c|c|c|c|c|c|c|c|c|}
\hline \multirow[t]{2}{*}{ categories } & & \multicolumn{2}{|c|}{ Low } & \multicolumn{2}{|c|}{ Intermediate } & \multicolumn{2}{|c|}{ High } & \\
\hline & & No. & $\%$ & No. & $\%$ & No. & $\%$ & \\
\hline Mild & 27 & 4 & 14.8 & 10 & 37 & 13 & 48.1 & $0.026^{*}$ \\
\hline Moderate & 18 & 1 & 5.6 & 5 & 27.8 & 12 & 66.7 & \\
\hline Severe & 71 & 1 & 1.4 & 16 & 22.5 & 54 & 76.1 & \\
\hline Total & 116 & 6 & 5.2 & 31 & 26.7 & 79 & 68.1 & \\
\hline
\end{tabular}

*By Fisher's exact test. Agreement $=54.3 \%$

+ GRACE:GlobalRegistry ofAcuteCoronary Events

Table 3.Rates of complications in different categories of troponin.

\begin{tabular}{|c|c|c|c|c|c|c|c|c|}
\hline & \multirow[t]{3}{*}{$\mathbf{N}$} & \multicolumn{6}{|c|}{ Troponin-I } & \multirow[t]{3}{*}{$\mathbf{p}$} \\
\hline & & \multicolumn{2}{|c|}{ Low } & \multicolumn{2}{|c|}{ Medium } & \multicolumn{2}{|c|}{ High } & \\
\hline & & No. & $\%$ & No. & $\%$ & No. & $\%$ & \\
\hline \multicolumn{9}{|c|}{ Serious Arrhythmias (VF/VT) } \\
\hline No & 103 & 24 & 100 & 17 & 100 & 62 & 93.9 & $0.467^{*}$ \\
\hline Yes & 4 & 0 & 0 & 0 & 0 & 4 & 6.1 & \\
\hline \multicolumn{9}{|c|}{ Heart block } \\
\hline No & 111 & 25 & 92.6 & 17 & 94.4 & 69 & 97.2 & $0.429 *$ \\
\hline Yes & 5 & 2 & 7.4 & 1 & 5.6 & 2 & 2.8 & \\
\hline \multicolumn{9}{|c|}{ In hospital death } \\
\hline No & 109 & 27 & 100 & 17 & 100 & 65 & 94.2 & $0.475^{*}$ \\
\hline Yes & 4 & 0 & 0 & 0 & 0 & 4 & 5.8 & \\
\hline Total & 113 & 27 & 100 & 17 & 100 & 69 & 100 & \\
\hline \multicolumn{9}{|c|}{ Cardiac arrest at admission } \\
\hline No & 112 & 27 & 100 & 18 & 100 & 67 & 94.4 & $0.472^{*}$ \\
\hline Yes & 4 & 0 & 0 & 0 & 0 & 4 & 5.6 & \\
\hline
\end{tabular}




\begin{tabular}{lcccccccc}
\hline Total & 116 & 27 & 100 & 18 & 100 & 71 & 100 & \\
KILLIP class & & & & & & & & \\
I & 66 & 19 & 70.4 & 8 & 44.4 & 39 & 54.9 & $0.011^{*}$ \\
II & 28 & 8 & 29.6 & 8 & 44.4 & 12 & 16.9 & \\
III & 17 & 0 & 0 & 2 & 11.1 & 15 & 21.1 & \\
IV & 5 & 0 & 0 & 0 & 0 & 5 & 7 & \\
\hline Total & 116 & 27 & 100 & 18 & 100 & 71 & 100
\end{tabular}

*By Fisher's exact test.

Table 4. Ventricular systolic dysfunction and ischemic mitral regurgitation diagnosed by transthoracic echocardiography versus troponin I level.

\begin{tabular}{|c|c|c|c|c|c|c|c|c|}
\hline & \multirow[t]{3}{*}{$\mathbf{N}$} & \multicolumn{6}{|c|}{ Troponin-I } & \multirow[t]{3}{*}{$\mathbf{p}$} \\
\hline & & \multicolumn{2}{|c|}{ Low } & \multicolumn{2}{|c|}{ Medium } & \multicolumn{2}{|c|}{ High } & \\
\hline & & No. & $\%$ & No. & $\%$ & No. & $\%$ & \\
\hline \multicolumn{9}{|l|}{ LVSD** $^{* *}$} \\
\hline No & 70 & 21 & 84 & 15 & 88.2 & 34 & 50.7 & 0.001 \\
\hline Yes & 39 & 4 & 16 & 2 & 11.8 & 33 & 49.3 & \\
\hline Total & 109 & 25 & 100 & 17 & 100 & 67 & 100 & \\
\hline \multicolumn{9}{|c|}{ Ischemic mitral regurgitation (IMR) } \\
\hline No MR & 72 & 23 & 85.2 & 13 & 72.2 & 36 & 50.7 & $0.055^{\star}$ \\
\hline Mild & 26 & 3 & 11.1 & 2 & 11.1 & 21 & 29.6 & \\
\hline Moderate & 14 & 1 & 3.7 & 2 & 11.1 & 11 & 15.5 & \\
\hline Severe & 4 & 0 & 0 & 1 & 5.6 & 3 & 4.2 & \\
\hline Total & 116 & 27 & 100 & 18 & 100 & 71 & 100 & \\
\hline
\end{tabular}




\section{${ }^{*}$ By Fisher's exact test. ${ }^{* *}$ There is missing data}

\section{Discussion}

This study was done as an attempt to evaluate the role of troponin I in predicting the in-hospital outcomes in patients with first STEMI.

Results showed that admission cTn-I was very high among males (66.2\%) compared with $(52.4 \%)$ of females $(p=0.002)$; our results goes in parallel with Shah et al; that study found that women were less likely to have biomarker evidence of myocyte necrosis, this can lead to under diagnosis of myocardial infarction in women and contribute to sex inequalities in treatments and outcomes [11].

The agreement rate between troponin levels and GRACE score in our study was $54.3 \%$. Some of the cases categorized as 'mild troponin' were categorized as 'high grace score'. Our findings are consistent with Bonaca et al study, which found low-level increment in cTnl using a sensitive assay identify patients at higher risk of death or MI [12].

In contrary to other studies, no significant association was found between in hospital death and cardiac arrest at admission with troponin level, but it is worth to mention that all deaths (four cases) were of high troponin level; this may be explained by small number of patients in this study. Entman et al found that the detection of the highly specific marker cardiac troponin I in blood is an independent risk factor that identifies patients presenting with acute coronary syndrome who are at increased risk of death [13].

Our study found that $7 \%$ of those with high troponin level developed cardiogenic shock (KILLIP class IV) compared with $0 \%$ among those with low and medium troponin level. In addition to that, $21.1 \%$ of those with high troponin developed KILLIP class III heart failure compared with $11.1 \%$ among those with medium troponin and $0 \%$ among those with low troponin, while the majority of those with low troponin level developed KILLIP class 1 and II $(p=0.011)$, our findings were consistent with Peacock et al study which found that patients with admission troponin I positive patients had lower systolic blood pressure and lower ejection fractions [14]. 
The incidence of early LVSD (49.3\%) was significantly higher among patients with high troponin levels $(P=0.001)$. Our results are consistent with other previous studies where high levels of admission cTnIwas associated with more severe heart failure, including worse left ventricular function, also troponins were associated with more severe symptoms, more need for aggressive supportive measures, including inotropic therapy, and worse outcomes $[14,15]$.

Conclusions: High admission cardiac troponin I in first ST-segment elevation myocardial infarction, permits the early identification of patients at increased risk of cardiac death, cardiogenic shock, acute pulmonary edema and early left ventricular systolic dysfunction.

\section{Conflicts of interest}

The authors report no conflicts of interest.

\section{References}

1.World Health Rankings[on line].Data source published by: WHO 2014[cited 24Feb 2016].Available from: www.worldlifeexpectency.com/cause-of-death/coronary-heart-dis/by-country.

2-Chapelle JP. Cardiac troponin I and T: recent players in the field of myocardial markers. ClinChem Lab Med.1999; 37:11-20.

3-Matetzky S, Sharir T, Domingo M, et al. Elevated troponin I level on admission is associated with adverse outcome of primary angioplasty in acute myocardial infarction. Circulation 2000; 102:1611-6.

4.Hamm CW, Goldman BU, Heeschen C, Kreymann G, Berger J, Meinertz T. Emergency room triage of patients with acute chest pain by means of rapid testing for cardiac troponin T or troponin I.N Engl J Med 1997; 337: 1648-53.

5-Hallen J, Jensen JK, Fagerland MW, et al. Cardiac troponin I for the prediction of functional recovery and left ventricular remodelling following primary percutaneous coronary intervention for ST-elevation myocardial infarction. Heart 2010;96:1892-7.

6. Thygesen K, Alpert JS, White HD, Jaffe AS, Apple FS, et al. Joint ESC/ACCF/AHA/WHF Task Force for the Redefinition of Myocardial Infarction, Universal definition of myocardial infarction.Circulation 2007; 116(22):2634-53. 
7-Killip T $3^{\text {rd }}$, Kimball JT. Treatment of myocardial infarction in a coronary care unit. A two year experience with 250 patients. Am J Cardiol. 1967;20(4):457-64.

8. Lang RM, Bierig M, Devereux RB, Flachskampf FA, Foster E, Pellika PA, et al. Recommendations for Chamber Quantification: A report from the American Society of Echocardiography's Guidelines and Standards Committee and the Chamber Qualification Writing Group, Developed in conjunction with the European Association of Echocardiography, a Branched of the European Society of Cardiology.J Am SocEchocardiogr 2005;18(12):1440-63.

9.Fuchs S,Kornowski R,Mehran R,Satler LF,PichardAD,Kent KM etal.CardiacTroponinl levels and clinical outcomes in patients with Acute Coronary Syndrome. JACC.1999; 34(6): 1704-10.

10.Hamm CW, Bassand JP, Agewall S, Bax J,Boersma E,Bueno H, et al.ESC Guidelines for the management of acute coronary syndromes in patients presenting without persistent ST-segment elevation. The Task Force for the management of acute coronary syndromes in patients presenting without persistent ST-segment elevation of the European Society of Cardiology(ESC).Eur Heart J 2011;32:2999-3054.

11- Shah AS, Griffiths M, Lee KK, McAllister DA, Hunter AL, Ferry AV et al. High sensitivity cardiac troponin and the under-diagnosis of myocardial infarction in women: prospective cohort study. BMJ 2015;DOI: 10.1136/bmj.g7873.

12-Bonaca M, Scirica B, Sabatine M, Dalby A, Spinar J, Murphy SA, et al. Prospective evaluation of the prognostic implications of improved assay performance with a sensitive assay for cardiac troponin I. J Am CollCardiol 2010; 55:2118-24. 
13.Antman EM, Tanasijevic MJ, Thompson B, Schactman M, McCabe CH, Cannon CP, et al.Cardiac -specific troponin I levels to predict the risk of mortality in patients with acute coronary syndromes. N Engl J Med 1996; 335:1342-9.

14- Xue Y, Clopton P, Peacock WF, Maisel AS. Serial changes in high- sensitive troponin I predict outcome in patients with decompensated heart failure. Eur J Heart Fail 2011; 13:37-42.

15- You JJ, Austin PC, Alter DA, Ko DT, Tu JV. Relation between cardiac troponin I and mortality in acute decompensated heart failure. Am Heart J 2007;153:462-70.

(C) 2016 by the authors; licensee Preprints, Basel, Switzerland. This article is an open access article distributed under the terms and conditions of the Creative Commons by Attribution (CC-BY) license (http://creativecommons.org/licenses/by/4.0/). 